\title{
"Metrics for NASA Aeronautics Research Mission Directorate (ARMD) Strategic Thrust 3B Vertical Lift Strategic Direction"
}

\author{
Ronald D. Hochstetler ${ }^{1}$ \\ SAIC, 400 Virginia Ave., SW; Suite 800, Washington, DC 20024 \\ Dan Salvano ${ }^{2}$ \\ SAIC, 400 Virginia Ave., SW; Suite 800, Washington, DC 20024 \\ Susan A. Gorton ${ }^{3}$ \\ NASA Langley Research Center, Mail Stop 254, Hampton, VA 23666
}

\begin{abstract}
The NASA Aeronautics Research Mission Directorate (ARMD) Strategic Implementation Plan details an ambitious plan for aeronautical research for the next quarter century and beyond. It includes a number of advanced technologies needed to address requirements of the overall aviation community (domestic and international), with an emphasis on safety, efficiency, operational flexibility, and alternative propulsion air transport options. The six ARMD Strategic Thrust Areas (STAs) represent a specific set of multi-decade research agendas for creating the global aviation improvements most in demand by the aviation service consumers and the general public. To provide NASA with a measurement of the preeminent value of these research areas, it was necessary to identify and quantify the measurable benefits to the aviation community from capabilities delivered by the research programs. This paper will describe the processes used and the conclusions reached in defining the principal metrics for ARMD Strategic Thrust Area 3B "Vertical Lift Strategic Direction."
\end{abstract}

\section{Introduction}

In response to the 2014 NASA Strategic Plan, strategic objective 2.1: "Enable a revolutionary transformation for safe and sustainable U.S. and global aviation by advancing aeronautical research" the Aeronautics Research Mission Directorate (ARMD) developed six Strategic Thrusts (ARMD, 2017) ${ }^{1}$. These thrusts provide guidance to research across a wide range of technology initiatives to help maintain the U.S. aeronautical leadership and support U.S. industry needs to be competitive in the international aviation marketplace. When taken in aggregate, they represent NASA's vision for the future of aeronautics. Subsequently, an effort was initiated by ARMD to identify metrics which NASA can use to measure the effectiveness and evaluate the benefits of the technologies developed under the ARMD Strategic Thrusts. Since the metrics must contribute to helping ARMD achieve its program goals, they must be useful in defining project outcomes, realistic industry impacts, and measurable technical challenges and risk for subprojects. The scope of this paper is to descibe the research conducted to identify metrics relevent to all the Strategic Thrusts and to use the example of Strategic Thrust 3B "Ultra-Efficient Commercial Vehicles--Vertical Lift Aircraft" (VLA) to illustrate the specifics of metric development.

The area of VLA development is expansive and impacts the smallest to the largest conceivable aircraft. The research is intended to improve performance and mission capabilities ranging from the very small unmanned aircraft systems (UASs) to ultra-heavy commercial transports (Figure 1). Principal emphasis is to be focused on improving current VLA performance (cost, speed, payload, safety, and noise) and opening new markets with new configurations and mission capabilities. Efforts would also be made to capitalize on the convergence of technology in electric propulsion, information technology, and reduced pilot workload or no pilot through greater use of autonomous systems.

Several research themes for Thrust 3B have been proposed by NASA. Clean and efficient propulsion can be pursued by advancing the efficiency of propulsion systems, and expanding the integration and development of alternative propulsion systems for vertical lift configurations. The development of more efficient and quieter vehicles could be realized from research and development of technologies and configurations that optimize performance and

\footnotetext{
${ }^{1}$ Senior Aerospace Engineer, Training \& Simulation, SAIC, Washington, DC 20024, Senior Member

${ }^{2}$ Aviation Consultant for Certification, Safety, and CNS, SAIC, Washington, DC, Associate Fellow

${ }^{3}$ Project Manager, NASA Revolutionary Vertical Lift Technology, Mail Stop 254, NASA Langley Research Center, Hampton, VA, Associate Fellow
}

American Institute of Aeronautics and Astronautics 
speed, while minimizing noise and cost. Safety, comfort, and accessibility is achieveable through research and development of technologies and capabilities that improve passenger (and public) safety during operations. This initiative would also investigate technologies that improve vehicle dynamic response, in addition to design configurations and operational concepts that improve access to transportation and services. Modeling and simulation tools, new experimental methods and testing capabilities are also considered instrumental in supporting analytical achievements in configuration design, development, certification, and operation.

\begin{tabular}{|c|c|c|c|c|c|}
\hline & Very Light & Light & Medium & Heavy & UltraHeavy \\
\hline \multirow[t]{2}{*}{ Missions } & $\begin{array}{l}\text { - Inspection } \\
\text { - Photography } \\
\text { - Filming } \\
\text { - Spraying } \\
\text { - Mapping } \\
\text { - Weather } \\
\text { - Surveillance } \\
\text { - Delivery }\end{array}$ & $\begin{array}{l}\text { - Police } \\
\text { - Training } \\
\text { - Traffic/news } \\
\text { - Power line } \\
\text { service } \\
\text { - Spraying } \\
\text { - Personal } \\
\text { - Air Taxi } \\
\text { - Cargo }\end{array}$ & $\begin{array}{l}\text { - Police } \\
\text { - EMS } \\
\text { - Traffic/news } \\
\text { - Tourism } \\
\text { - Executive } \\
\text { - Charter } \\
\text { - Oil Platforms } \\
\text { - SAR } \\
\text { - Cargo }\end{array}$ & $\begin{array}{l}\text { - Oil platforms } \\
\text { - Disaster relief } \\
\text { - Cargo } \\
\text { - Logging } \\
\text { - Construction } \\
\text { - Firefighting } \\
\text { - Commuter } \\
\text { (30 pax) }\end{array}$ & $\begin{array}{l}\text { - Commercial } \\
\text { transport } \\
(90-120 \text { pax }) \\
\text { - Disaster relief } \\
\text { - Civil reserve } \\
\text { aircraft fleet } \\
\text { - Cargo }\end{array}$ \\
\hline & \multicolumn{5}{|c|}{ autonomous capability } \\
\hline $\begin{array}{l}\text { Overarching } \\
\text { Vertical Lift } \\
\text { Strategy }\end{array}$ & \multicolumn{5}{|c|}{$\begin{array}{l}\text { Enable a broad expansion of vertical lift applications } \\
\text { - Improve current configuration cost, speed, payload, safety, and noise } \\
\text { - Open new markets with new configurations and capability } \\
\text { - Capitalize on convergence of technology in electric propulsion, autonomy and flight controls }\end{array}$} \\
\hline
\end{tabular}

Blue Highlight: New mission and/or new configuration

Fig. 1. NASA Envisioned Common Civil Configurations and Missions in 2030 \& Beyond

\section{Understanding Thrust 3B Roadmap, Statements, and References}

Understanding the proper scope for this task was essential to avoid delving into undue technical details or developing unwieldy or irrelevant measurements. The Thrust 3B metrics also needed to capture the nuances that are introduced by progress towards higher fidelity or different types of technologies or operational capabilities. Initiating this effort required development of a method for defining the Thrust metrics through a step-by-step metrics generation approach. A further delineation was also needed to associate the metrics of Thrust 3B directly to the "Outputs" that will result from the ARMD research, and connect to the VLA community "Outcomes" that are the ultimate objectives of the ARMD research.

\section{A. An Initial Literature Search}

An extensive literature review was conducted to identify relevant publications and reports from NASA, FAA, the International Civil Aviation Organization (ICAO), the International Air Transport Association (IATA), aircraft original equipment manufacturers (OEMs), operators, and customers. This search effort was focused on potentially relevant aircraft performance and operational metrics used in investigations by a broad range of organizations. It also sought out the most recent and relevant aviation market assessments and future trends reports that show what directions the VLA industry is considering. The literature collected provided the fundamental understanding of the measurement development scope, and it set the stage for the subsequent delineation of the Thrust $3 \mathrm{~B}$ measurements.

\section{B. Decomposition of Roadmaps, Benefits, Outcomes, and Capabilities Statements}

Concurrent with the literature search was the definition of an expanded set of quantifiable benefits that can be used to describe targeted community Outcomes. This called for a complete review of the ARMD research Roadmaps, community Outcome statements, Benefit statements, and Output/Capabilities statements for all the Strategic Thrusts, including Thrust 3B (Susan Gorton, 2016) ${ }^{2}$.

The ARMD Roadmaps are designed to guide both specific research and staged technology deployment into the aviation community and the NAS to provide increasing capability over three epochs. The ARMD SIP offers a definition of the community Outcomes in three timeframes, or epochs, in which research results are transitioned from concept to practice:

American Institute of Aeronautics and Astronautics 
- Near-term (2015-2025). Outcomes generally leverage partnerships to demonstrate feasibility of potential applications. They enjoy a greater degree of confidence within the aviation community and generally involve focused technology partnerships to enable the outcomes.

- Mid-term (2025-2035). Outcomes are often in a transitional stage, aimed at a combination of new concepts and applications within the current system. They reflect applications of emerging technologies, initially within the paradigm of the existing aviation system, but often leading to transformative innovations responsive to future needs.

- Far-term (>2035). Outcomes are more exploratory in nature, focusing on concept exploration and technology research. For these outcomes, ARMD takes a greater role in performing and sponsoring concept exploration and fundamental research.

ARMD Benefit statements describe high-level Outcomes and vision from the stakeholder community perspective; the Output/Capabilities statements provide high-level descriptions of expected capabilities that the research will enable and the output that will be provided to the aviation industry and the NAS. Because the ARMD Thrust roadmaps are "community" roadmaps, meaning not just NASA contributions, they reflect the role of other stakeholders such as the FAA, aircraft OEMs, the DOD, other countries, and aircraft operators. Considering how much research is underway, any significant gaps in development needs to be identified and addressed. It is essential not to overlook the "big" technical challenges and critical "decision points" that are clearly identified in the Roadmaps. While most of the technical challenges are addressed at the individual project level, ARMD is also looking for higher level technical challenges that may also pose potential hurdles to achieving full system capabilities.

To utilize the insights available from the Thrust 3B Roadmap, and the Benefit and Capabilities statements, it was necessary to decompose the various Roadmaps and statements to obtain those elements that can be directly tied to a specific set of metrics. For this task a three-step process (Figure 4) was developed (Discovery $>$ Decomposition $>$ Validation) to identify metrics for each of the benefit statements in ARMD's Thrust 3B research roadmap.

STEP 1: Discovery

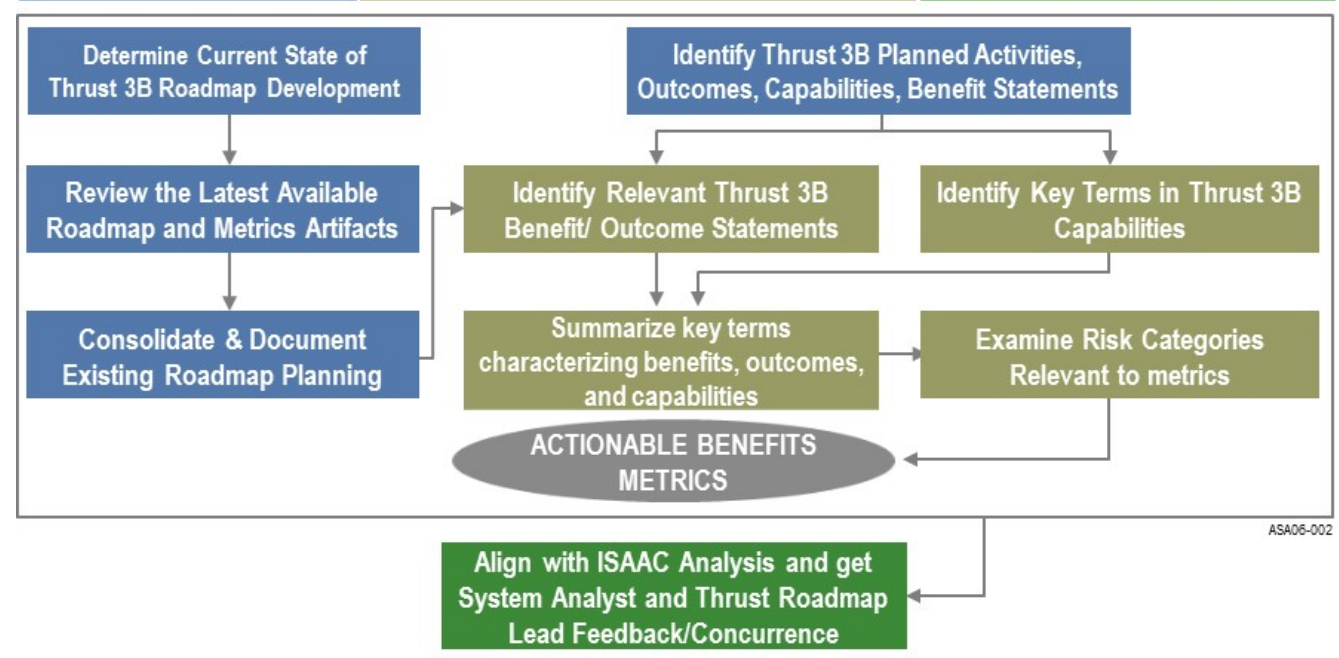

Figure 1. 3-Step Process for Decomposing Benefits Statements.

The first step (Discovery) required a review of the ARMD Strategic Thrust 3B Roadmap to determine the elements of the Thrust and assess them for their initial, relevant metrics. A review was made of the latest Strategic Thrust Roadmap plans, existing metrics documentation, and information on Strategic Thrust planned Community Outcomes and Benefits. Next an identification was made of the planned research activities, expected outcomes across the three epochs, and the Capabilities and Benefits that were identified for Thrust 3B. The Benefit statements aided in validating or modifying the understanding of these statements in light of the relevant resources uncovered during the literature search. Sometimes a clear definition of activities in the statements was not available or insufficiently apparent for the purpose of decomposing into metrics. To compensate for this, we leveraged our team's broad and extensive expertise (along with inputs from the respective NASA personnel) to define/refine/expand on those issues. The second step required the decomposition of the Thrust 3B Roadmap (Figure 5) and Community Outcomes, Benefits, and NASA Strategies \& Capabilities statements (Figure 6) to extract exact definitions of expected Thrust 3B benefits.

American Institute of Aeronautics and Astronautics 


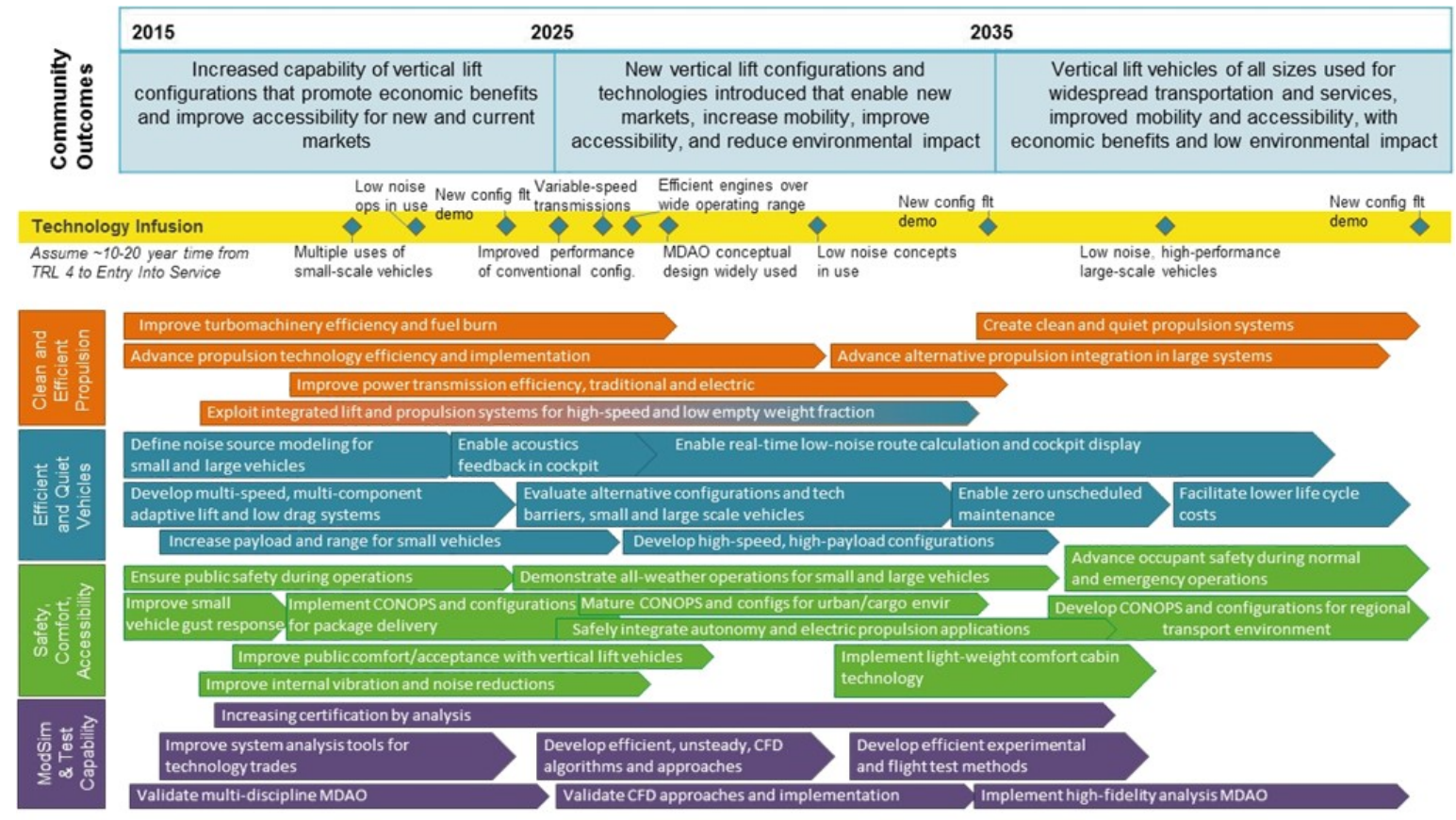

* Detailed technical content of the Research Themes will be determined by individual projects through applying periodic system analysis, concept evaluation, technology assessments, subject matter expert evaluation, and community interest. Specific Technical Challenges will be proposed to address the roadmap objectives

Figure 2. Roadmap for Thrust 3B.

\begin{tabular}{|c|c|c|c|}
\hline \multicolumn{4}{|c|}{ Strategic Thrust 3B: Ultra-Efficient Commercial Vehicles - Vertical Lift } \\
\hline \multicolumn{2}{|c|}{2015} & 2025 & 2035 \\
\hline 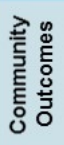 & $\begin{array}{l}\text { Increased capability of vertical lift configurations } \\
\text { that promote economic benefits and improve } \\
\text { accessibility for new and current markets }\end{array}$ & $\begin{array}{l}\text { New vertical lift configurations and } \\
\text { technologies introduced that enable new } \\
\text { markets, increase mobility, improve } \\
\text { accessibility, and reduce environmental } \\
\text { impact }\end{array}$ & $\begin{array}{l}\text { Vertical lift vehicles of all sizes used for } \\
\text { widespread transportation and services, } \\
\text { improved mobility and accessibility, with } \\
\text { economic benefits and low environmental } \\
\text { impact }\end{array}$ \\
\hline 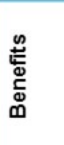 & $\begin{array}{l}\text { Reduction in direct operating cost, increased } \\
\text { accessibility to sensitive areas, and growth in } \\
\text { new and current markets enabled by } \\
\text { improvements to performance, efficiency and } \\
\text { noise. }\end{array}$ & $\begin{array}{l}\text { New markets and applications enabled by } \\
\text { unique technologies and configurations. } \\
\text { Mobility and accessibility increased through } \\
\text { reliable, safe and quieter operation in a wider } \\
\text { range of locations and conditions. }\end{array}$ & $\begin{array}{l}\text { Economic, environmental, and public } \\
\text { benefits realized through a spectrum of } \\
\text { vertical lift vehicle configurations that } \\
\text { provide services, transportation, and } \\
\text { unique mission capability. }\end{array}$ \\
\hline 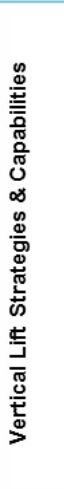 & $\begin{array}{l}\text { Deliver key capabilities and technologies that } \\
\text { directly benefit our partners in industry and } \\
\text { government } \\
\text { - Validated tool for modeling noise from entire } \\
\text { vehicle } \\
\text { - Validated tools for multi-discipline vehicle } \\
\text { design, analysis and optimization } \\
\text { - Tools for mission analysis and configuration } \\
\text { trade studies } \\
\text { - Technologies for pilot workload reduction } \\
\text { - Design for improved turbomachinery } \\
\text { - efficiency } \\
\text { - Approach for high power-transmission } \\
\text { - Lower drag for increased speed, range, } \\
\text { payload and lower fuel burn }\end{array}$ & $\begin{array}{l}\text { Focus on key technologies that enable US } \\
\text { industry to expand the global vertical lift } \\
\text { market while setting new standards in noise, } \\
\text { performance and reliability } \\
\text { - Process to characterize and predict human } \\
\text { response to noise } \\
\text { - Validated tool to calculate acoustic footprint } \\
\text { in real-time } \\
\text { - Efficient alternative propulsion options } \\
\text { - On-board systems to enhance safe } \\
\text { operations in icing conditions, degraded } \\
\text { visual environments and confined or urban } \\
\text { areas } \\
\text { - Validated, high-fidelity computational } \\
\text { algorithms for full configuration simulations } \\
\text { - Tools for mission analysis and concept of } \\
\text { operations (CONOPS) for unconventional } \\
\text { configurations }\end{array}$ & $\begin{array}{l}\text { Focus on capabilities and technologies } \\
\text { that eliminate barriers for clean, efficient, } \\
\text { quiet, autonomous vehicles operating in } \\
\text { urban and isolated environments } \\
\text { - Best practices for integration of lift anc } \\
\text { propulsion systems } \\
\text { - Methods for real-time low-noise } \\
\text { operations } \\
\text { - Active and prognostic condition-based } \\
\text { maintenance systems to reduce life- } \\
\text { cycle costs } \\
\text { - Methodology to analytically certify } \\
\text { composite primary structure for loads } \\
\text { and impact response } \\
\text { - Advanced experimental methods for } \\
\text { ground and flight test validation of } \\
\text { configurations }\end{array}$ \\
\hline
\end{tabular}

Figure 3. Community Outcomes, Benefits, and Capabilities Statement for Thrust $3 B$.

The Thrust 3B Benefit statements and Output/Capabilities statements were subsequently decomposed, and the key benefits identified (highlighted bold in Figures 7 and 8). This task defined those vertical lift aircraft (VLA) benefits and metrics that show measurable and beneficial community outcomes. It also focused on the research developments NASA has determined are most needed to broaden and enable the availability and capability of small to very large VLAs.

American Institute of Aeronautics and Astronautics 


\begin{tabular}{|l|l|l|}
\hline \multicolumn{2}{|c|}{ Strategic Thrust 3B: Vertical Lift } \\
\hline \multicolumn{1}{|c|}{ Near Term } & \multicolumn{1}{|c|}{ Mid Term } & \multicolumn{1}{c|}{ Far Term } \\
Reduction in direct operating & New markets and & Economic, environmental, and \\
cost, increased accessibility to & applications enabled by & public benefits realized through \\
sensitive areas, and growth in & unique technologies and & a spectrum of vertical lift vehicle \\
new and current markets & configurations. Mobility and \\
enabled by improvements to & accessibility increased & configurations that provide \\
performance, efficiency and & through reliable, safe and & services, transportation, and \\
noise. & quieter operation in a wider & \\
& range of locations and & \\
\end{tabular}

Figure 7. Decomposition of Outcomes and Benefits for Thrust 3B.

\begin{tabular}{|c|c|c|}
\hline \multicolumn{3}{|c|}{ Thrust 3B: Vertical Lift } \\
\hline Near Term & Mid Term & Far Term \\
\hline $\begin{array}{l}\text { Deliver key capabilities and } \\
\text { technologies that directly benefit } \\
\text { our partners in industry and } \\
\text { government } \\
\text { - Validated tool for modeling } \\
\text { noise from entire vehicle } \\
\text { - Validated tools for multi- } \\
\text { discipline vehicle design, } \\
\text { analysis and optimization } \\
\text { - Tools for mission analysis and } \\
\text { configuration trade studies } \\
\text { - Technologies for pilot workload } \\
\text { reduction } \\
\text { - Design for improved } \\
\text { turbomachinery efficiency } \\
\text { - Approach for high power- } \\
\text { transmission efficiency } \\
\text { established } \\
\text { - Lower drag for increased } \\
\text { speed, range, payload and } \\
\text { lower fuel burn }\end{array}$ & $\begin{array}{l}\text { Focus on key technologies that enable } \\
\text { US industry to expand the global } \\
\text { vertical lift market while setting new } \\
\text { standards in noise, performance and } \\
\text { reliability } \\
\text { - Process to characterize and predict } \\
\text { human response to noise } \\
\text { - Validated tool to calculate acoustic } \\
\text { footprint in real-time } \\
\text { - Efficient alternative propulsion } \\
\text { options } \\
\text { - On-board systems to enhance safe } \\
\text { operations in icing conditions, } \\
\text { degraded visual environments and } \\
\text { confined or urban areas } \\
\text { - Validated, high-fidelity } \\
\text { computational algorithms for full } \\
\text { configuration simulations } \\
\text { - Tools for mission analysis and } \\
\text { concept of operations (CONOPS) for } \\
\text { unconventional configurations }\end{array}$ & $\begin{array}{l}\text { Focus on capabilities and } \\
\text { technologies that eliminate } \\
\text { barriers for clean, efficient, quiet, } \\
\text { autonomous vehicles operating in } \\
\text { urban and isolated environments } \\
\text { - Best practices for integration } \\
\text { of lift and propulsion systems } \\
\text { - Methods for real-time low- } \\
\text { noise operations } \\
\text { - Active and prognostic } \\
\text { condition-based maintenance } \\
\text { systems to reduce life-cycle } \\
\text { costs } \\
\text { - Methodology to analytically } \\
\text { certifycomposite primary } \\
\text { structure for loads and } \\
\text { impact response } \\
\text { - Advanced experimental } \\
\text { methods for ground and flight } \\
\text { test validation of } \\
\text { configurations }\end{array}$ \\
\hline
\end{tabular}

Figure 8. Decomposition of Output and Capabilities for Thrust 3B.

\section{Combining Metrics}

Metrics related to multiple capabilities were then combined to develop a unified set of metrics for Thrust 3B. The relative contributions to benefit metrics by individual capabilities were also assessed and investigated to determine if additional metrics were needed to account for this combined effect. Following these decompositions a summation was made of the research activities planned for Thrust 3B outcomes projected over the three epochs. Figure 9 lists the key research output and outcome elements of Thrust 3B for which particular metrics could now be developed.

American Institute of Aeronautics and Astronautics 
Epoch 1 would begin with the development of validated tools and approaches to support research into a range of investigations. The tools would assist in exploring reductions in drag, fuel consumption, carbon emissions, noise, direct operating costs (DOC), and pilot workload. Increased VLA speed, range, payload, propulsion system efficiency, and accessibility to a range of locations would also benefit from this enhanced set of modeling and simulations tools. This analytical body of work would in addition enable the establishment of system enhancements (such as pilot automation support) that optimize aircraft operations, improve safety, and promote growth in current and new markets.

Epoch 2 will deal with identifying key technologies, processes, and tools that would enable US industry to increase mobility, accessibility, reliability, and operate in wider range of locations, conditions, markets, and applications. It is anticipated that new VLA designs in this epoch could employ unique technologies, configurations, and efficient alternative propulsion options, enhanced safety in icing conditions, degraded visual environments, and operations into confined or urban areas. Models would be sufficiently mature to allow simulations for mission analysis and concept of operations (CONOPS) development for unconventional VLA configurations and new markets.

In epoch 3 the tools and engineering capabilities, technologies, practices, and analytical methodologies produced so far would result in the elimination of development barriers that have hindered VLA manufactures. At this point in time the VLA developers would be able to employ the tools and technical insights that were outputs from the Thrust 3B research. Applying tools and technology from the NASA research, the manufacturers will be able to design multiple vehicle configurations having unique mission capabilities that offer improved economic, environmental, and public benefits. Integrated lift and propulsion systems, low-noise operations, and reduced life-cycle costs can also be realized in this epoch by the VLA industry. In addition, mature analytical methodologies will be available for certifying composite primary structures, and validating ground $\&$ flight test configurations.

\section{Epoch 1}

Validated tools and approaches to support:

Reductions in drag, fuel consumption, carbon emissions, noise, direct operating costs (DOC), and pilot workload Increased speed, range, payload, propulsion system efficiency, and accessibility to a range of locations

Enhancements (such as pilot automation support) that optimize aircraft operations, improve safety, and promote growth in current and new markets

\section{Epoch 2}

Key technologies, processes, and tools that will enable US industry to:

Increase mobility, accessibility, reliability, and operate in wider range of locations, conditions, markets, and applications

Employ unique technologies, configurations, and efficient alternative propulsion options

Enhance safety in icing conditions, degraded visual environments, and confined or urban areas

Conduct simulations for mission analysis and CONOPS for unconventional configurations

\section{Epoch 3}

Capabilities, technologies, practices, and analytical methodologies that eliminate barriers to developing: Multiple vehicle configurations with unique mission capabilities offering economic, environmental, and public benefits

Integrated lift and propulsion systems, low-noise operations, and reduced life-cycle costs

Analytical methodologies for certifying composite primary structures, and validating ground \& flight test configurations

Figure 9. Benefits and Capabilities Concepts for Thrust 3B from Decomposition Efforts.

\section{Reviewing Past and Current Work on Aviation Metrics}

With the establishment of a refined compilation of intended Thrust accomplishments, the published information resources identified during the initial literature search were then analyzed for any additional inputs that could assist in identifying appropriate metrics. The wealth of previously published NASA research was invaluable in providing additional understanding of many of the issues that govern the creation of useful and practical metrics. Some of the most insightful observations were found in reports and projections by major participants in the aeronautical markets (principally OEMs and aircraft operators). They provided a rich source for understanding what the VLA community perceived their future needs to be. Figure 10 provides a subset of the many types of research and information resources that were accessed for Thrust 3B.

American Institute of Aeronautics and Astronautics 
1. AIAA Paper 2015-0949, "NASA Technology for Next Generation Vertical Lift Vehicles", Susan Gorton, S.; López, I.; Theodore, C.:, AIAA 53rd Aerospace Science Meeting, Kissimmee, Jan. 59, 2015

2. "NASA Heavy Lift Rotorcraft Systems Investigation", Wayne Johnson and Gloria K. Yamauchi, Ames Research Center, Moffett Field, California, Michael E. Watts, Langley Research Center, Hampton, Virginia, NASA/TP-2005-213467

3. "Validating ARMD Analytical Framework Measures", Briefing to NASA ARMD Analysis Board, by George Price, Crown Consulting Inc., March 14, 2013

4. AIAA Paper 2016-3767, "Economics of Advanced Thin-Haul Concepts and Operations", Anusha Harish, Christian Perron, Daniel Bavaro, Jai Ahuja, Melek D. Ozcan, Cedric Y. Justiny, Simon Bricenoz, Brian J. Germanx and Dimitri Mavris, AIAA Aviation, 16th AIAA Aviation Technology, Integration, and Operations Conference, 13-17 June 2016, Washington, D.C.

5. Future Rotorcraft Technology Needs, Aerospace Symposium, University of Glasgow, 3rd November 2015

6. "The Future of Urban Mobility", AIRBUS Group, 2016

7. "What's Ahead for Vertical Aviation? OEMs Flight-Plan for the Future", by Robert W. Moorman, ROTOR magazine, Winter 2015

8. "Why helicopter airliners haven't happened - yet", Stephen Dowling, BBC.com, 27 May, 2016

Figure 40. Supporting Reference Documents for Thrust 3B.

Information extracted from the reference materials confirmed many of the primary objectives and goals stated in the Thrust 3B Benefits, Output/Capabilities statements, and research Roadmap. They also provided some indication of the strength of demand among VLA manufacturers and operators for much of the research outputs the Strategic Thrusts are investigating. Figure 11 highlights the principal research in Thrust $3 \mathrm{~B}$ that would be most relevant to the civil aviation community. Figure 12 presents some of the expectations that this community has for new aviation technologies and indicates the particular benefits they would be most interested in from the Thrust 3B technological advancements.

Vertical Lift Aircraft (VLA) capabilities producing attributes in high demand by the aviation community:

- Better quantities of high power-to-weight, energy efficient propulsion systems

- Enables: larger payloads, greater speed, range, and endurance and reduces life-cycle carbon emissions. Reduced fuel/energy usage and lower operating costs

- Aerodynamically-efficient structural designs optimally incorporating advanced propulsion systems

- Enables: larger payloads, greater speed, range, and endurance. Reduced fuel and electric energy usage. Reduces life-cycle carbon emissions, and increases access to sensitive areas (due to reduced noise)

- Enhanced maneuverability and flight control through greater reliance on autonomous systems

- Enables: expanded operational envelope, improved safety, ability to meet growing demand for access to high population areas

- Increasing levels of automation; reduce pilot workload, improving safety

- Enables reduced pilot workload - "carefree handling"

- Exploitation of new materials and processes

- Enables: reduced weight, cost and development time

Figure 11. VLA capabilities producing attributes in high demand by the aviation community.

- Reduced Environmental Impact

- Improved Comfort, Vibration, Internal Noise, Cabin Environment, $\mathrm{CO} 2$ \& NOx Emissions, External Noise

- Improved Safety, Reliability, Survivability, Flaw Tolerance

- Reduced Cost of Ownership

- Improved Availability \& Maintainability

- Lower Acquisition \& Direct Operating Costs

- Increased Operational Capability

- Improved Payload, Range, Endurance, All Weather Operation, Speed

Figure 12. Civilian VLA industry perceived benefits from VLA research outputs.

American Institute of Aeronautics and Astronautics 


\section{E. Two Levels of Metrics - Output and Outcome}

The derived metrics fell into two distinct divisions: Output metrics and Outcome metrics. Output metrics were those that represented the results or products of the Strategic Thrust research specified in the ARMD roadmaps. These are the metrics associated with the development of tools, methodologies, knowledge, and design insights of direct use to manufacturers and operators of advanced aircraft. For Thrust 3B the Output metrics include: development of modeling and simulation tools, CONOPS, and configuration trade studies, or validated tools for modeling vehicle noise.

Outcome metrics are associated with the enhancement of OEM manufacturer's abilities to develop advanced capability aircraft. They also measure the extent to which aircraft operators are enabled or incentivized to incorporate the new aircraft into widespread use and new service areas. Thrust 3B Outcome metrics would include greater number and varied sizes of VLAs operating in a wider range of locations, conditions, and markets with reduced life-cycle costs and lower direct operating costs (DOC).

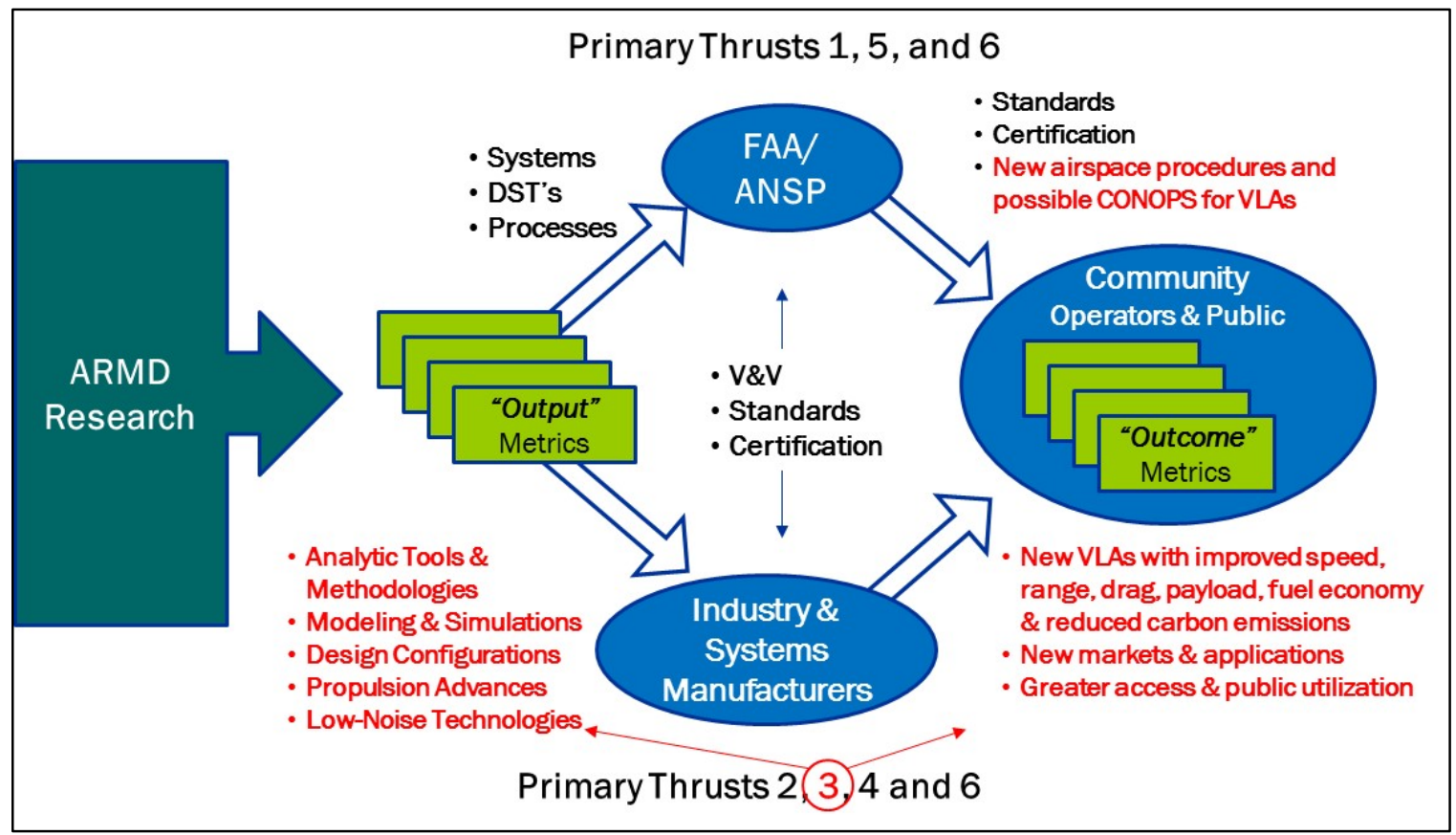

Figure 13. Two Levels of Metrics for Thrust 3B.

Once the Output metrics were identified, they could be directly associated with a set of Outcome metrics that represented the capabilities and eventual developments that had been identified as being of greatest value to the aviation community and general public. Figure 13 illustrates the differences between Output and Outcome metrics for Thrust 3B.

\section{F. Metrics Validation and Harmonization}

An important validation step was conducted which involved interviews with individual Thrust roadmap leads and Integrated Systems Analysis and Assessment Capability (ISAAC) analysts, to review the metrics defined for the respective Thrusts. The definitions of benefit metrics were presented to ARMD and ISAAC analysts and their guidance was solicited on the metrics capabilities to measure the relevant outputs and outcomes. Understanding how various benefit metrics impact different stakeholders was an important consideration in this project. Feedback was specifically solicited on any gaps or overlaps that may not have been accounted for in the analysis of the Strategic Thrust benefits or capabilities. An effort was also made to ensure the metrics followed the "criteria for defining good metrics" as detailed by NASA (Neitzke) ${ }^{3}$. These criteria include: providing direct indicators of progress towards one or more strategic goals, includes measurement assumptions and definitions, can be used to measure performance of future

American Institute of Aeronautics and Astronautics 
concepts against current-day operations, etc.- -in general, following the traditional "Specific, Measurable, Attainable, Realistic, Timely" (SMART) criteria for good metrics (NASA, n.d.). ${ }^{4}$

The Thrust 3B metrics were well defined and consistently measured across Thrust areas. However, because many metrics apply to multiple Thrusts, an alignment was established across the portfolio of six Thrusts by mapping specific benefit metrics directly to the Thrusts and those instances in which benefits overlap. An important aspect of this alignment analysis involved specifying when tradeoffs across Roadmaps may occur. For example, VLAs can improve access and mobility, but at potentially higher cost. Identifying these impacts across the entire ARMD research portfolio provides useful information to ARMD decision makers and highlights analyses to be performed by ARMD systems analysts.

\section{G. Consolidated List of Metrics}

A "Top-Level" set of metric definitions for all the Thrusts was developed to describe a generally high-level or "rounded up" measurement that, in some cases, was based on the amalgamation of several (inferred) lower-level individual measurements. Top-Level metrics represent those most relevant for use at the Strategic Portfolio Management Review (SPMR) Dashboard level, while the Mid-Level metrics provide quantifiable measures which may be unique to a given Thrust. Consolidation of metrics across all the Strategic Thrusts resulted in too many metrics to manage at the SPMR level. Though this refinement process, redundancies were eliminated and consistent terminology was applied to create a smaller set of 14 Top-Level metrics. The same approach was also applied for development of a set of "Mid-Level" metrics which are more directly related to an individual Thrust. Table 1 lists the common set of Top-Level metrics.

Table 1. List of Common Top-Level Metrics

\begin{tabular}{|l|l|}
\hline TOP-LEVEL METRIC & METRIC DEFINITION \\
\hline Accessibility & $\begin{array}{l}\text { Time and costs to access transportation modes and percentage increase in global } \\
\text { markets and city pairs served. }\end{array}$ \\
\hline Affordability & Passenger cost of commercial airline transportation. \\
\hline Air Traffic Management & Efficient air transportation system. \\
\hline Emissions & Environmental impact of aircraft fleet emissions and noise. \\
\hline Energy Intensity & Energy consumed/revenue ton-mile or revenue passenger-mile. \\
\hline $\begin{array}{l}\text { Hazard Precursor } \\
\text { Events }\end{array}$ & Precursor events in airspace and aircraft operations that increase risk. \\
\hline Life Cycle Cost & Life cycle capital investment and operating costs. \\
\hline $\begin{array}{l}\text { NAS Monitoring } \\
\text { Efficiency }\end{array}$ & NAS operations monitored continuously and latency of return to normal operations. \\
\hline $\begin{array}{l}\text { New Markets and } \\
\text { Applications }\end{array}$ & $\begin{array}{l}\text { New aviation business models, applications, and aircraft capabilities integrated into } \\
\text { the NAS and global operations. }\end{array}$ \\
\hline Noise & Exposure to engine and airframe noise for aircraft operations. \\
\hline Risk Mitigation & Reductions in the likelihood of system failures and severity of impact on operations. \\
\hline Safety of Flight & Aircraft system reliability and controllability to improve overall flight safety. \\
\hline State of the Art & Level of ARMD capabilities in key technology areas. \\
\hline Synergy with DoD & $\begin{array}{l}\text { Technology transfer opportunities between DOD and NASA and the extent of } \\
\text { technology adoption. }\end{array}$ \\
\hline
\end{tabular}

Table 2 was constructed to capture all the metrics most relevant to the Thrust 3B program objectives. Many of these metrics also intersect or are dependent on the NASA ARMD research outlined in several of the other Strategic Thrusts.

American Institute of Aeronautics and Astronautics 
Table 2. Metrics for Thrust 3B

\begin{tabular}{|c|c|c|c|}
\hline $\begin{array}{l}\text { TOP- } \\
\text { LEVEL } \\
\text { METRIC }\end{array}$ & $\begin{array}{l}\text { MID-LEVEL } \\
\text { METRIC }\end{array}$ & $\begin{array}{l}\text { METRIC } \\
\text { DEFINITION/UNITS }\end{array}$ & ASSUMPTIONS/COMMENTS \\
\hline Accessibility & $\begin{array}{l}\text { Access to } \\
\text { Sensitive or } \\
\text { Congested Areas }\end{array}$ & $\begin{array}{l}\text { Percent change in number } \\
\text { of VLA operations into } \\
\text { sensitive or restricted } \\
\text { areas. }\end{array}$ & $\begin{array}{l}\text { Metric is impacted by pace of new local } \\
\text { regulations allowing expanded VLA missions } \\
\text { and operations into new or previously restricted } \\
\text { areas. }\end{array}$ \\
\hline Emissions & $\begin{array}{l}\mathrm{CO}_{2}, \mathrm{NOx}, \text { and } \\
\text { Particulates }\end{array}$ & $\begin{array}{l}\text { Units of } \mathrm{CO}_{2}, \mathrm{NOx} \text {, and } \\
\text { particulates emitted per } \\
\mathrm{kW} \text { of energy consumed. }\end{array}$ & $\begin{array}{l}\text { Increased utilization of low-carbon "life-cycle" } \\
\text { fuels and electric propulsion. Local air quality } \\
\text { during landing and takeoff especially for NOx } \\
\text { emissions are important. }\end{array}$ \\
\hline \multirow{3}{*}{$\begin{array}{l}\text { Energy } \\
\text { Intensity }\end{array}$} & $\begin{array}{l}\text { Aerodynamic } \\
\text { Drag }\end{array}$ & Lift/drag ratio. & \\
\hline & $\begin{array}{l}\text { Fuel or } \\
\text { Electricity } \\
\text { Consumption }\end{array}$ & $\begin{array}{l}\text { Rate of fuel or electricity } \\
\text { consumption per flight } \\
\text { hour. }\end{array}$ & $\begin{array}{l}\text { Reducing aerodynamic drag and hence gaining a } \\
\text { reduction in the energy required to fly at a given } \\
\text { speed and weight, or through increased } \\
\text { propulsion system efficiencies that reduced the } \\
\text { amount of fuel or electricity needed. }\end{array}$ \\
\hline & $\begin{array}{l}\text { Propulsion } \\
\text { System Efficiency }\end{array}$ & $\begin{array}{l}\text { Engine power-to-weight } \\
\text { ratio and measure of } \\
\text { power loss from rotor } \\
\text { transmission. }\end{array}$ & \\
\hline \multirow{2}{*}{$\begin{array}{l}\text { Life Cycle } \\
\text { Cost }\end{array}$} & $\begin{array}{l}\text { Capital } \\
\text { Investment }\end{array}$ & $\begin{array}{l}\text { Cost of aircraft and } \\
\text { infrastructure. }\end{array}$ & \multirow{2}{*}{$\begin{array}{l}\text { A prognostic condition-based maintenance } \\
\text { program would enhance cost reductions. }\end{array}$} \\
\hline & Operating Cost & $\begin{array}{l}\text { Cost of seat-mile or cost of } \\
\text { trip. }\end{array}$ & \\
\hline \multirow{5}{*}{$\begin{array}{l}\text { New } \\
\text { Markets } \\
\text { and } \\
\text { Applications }\end{array}$} & $\begin{array}{l}\text { Industry } \\
\text { Adoption of } \\
\text { VLAs }\end{array}$ & $\begin{array}{l}\text { Rate of industry expansion } \\
\text { into new VLA missions. }\end{array}$ & $\begin{array}{l}\text { Metric is impacted by pace of new local } \\
\text { regulations allowing expanded VLA missions } \\
\text { and operations. }\end{array}$ \\
\hline & $\begin{array}{l}\text { Multiple Ultra } \\
\text { Efficient Vertical } \\
\text { Lift Vehicle } \\
\text { Configurations in } \\
\text { Service }\end{array}$ & $\begin{array}{l}\text { Total number of VLA } \\
\text { applications and vehicles } \\
\text { in service per year. }\end{array}$ & $\begin{array}{l}\text { Number and variety of markets and applications } \\
\text { enabled by advanced technology VLAs. Metric } \\
\text { is impacted by pace of new local regulations } \\
\text { allowing expanded VLA markets and } \\
\text { applications. }\end{array}$ \\
\hline & $\begin{array}{l}\text { Preferred } \\
\text { Transportation } \\
\text { Mode }\end{array}$ & $\begin{array}{l}\text { Total number of VLA trips } \\
\text { per year displacing other } \\
\text { modes of transportation. }\end{array}$ & $\begin{array}{l}\text { Measures VLA potential to replace less } \\
\text { efficient, less safe transportation modes on short } \\
\text { distance trips ( } 500 \text { miles or less). For example, } \\
\text { increased use of VLA applications and markets } \\
\text { could displace fixed-wing aircraft and ground } \\
\text { transport. }\end{array}$ \\
\hline & $\begin{array}{l}\text { Range of } \\
\text { Operations }\end{array}$ & $\begin{array}{l}\text { Max range at max aircraft } \\
\text { weight at best cruise } \\
\text { airspeed. }\end{array}$ & \\
\hline & $\begin{array}{l}\text { VLA Passenger } \\
\text { Usage }\end{array}$ & $\begin{array}{l}\text { Percent change in total } \\
\text { annual number of VLA } \\
\text { passenger seats/hours. }\end{array}$ & $\begin{array}{l}\text { Perceived Safety - increased public confidence } \\
\text { and trust in VLAs. }\end{array}$ \\
\hline Noise & $\begin{array}{l}\text { Ground, In- } \\
\text { Flight, and Cabin } \\
\text { Noise }\end{array}$ & $\begin{array}{l}\text { FAA Part } 150, \text { Part } 161, \\
\text { and Part } 36 .\end{array}$ & No FAA standards for "cabin" noise. \\
\hline \multirow{2}{*}{$\begin{array}{l}\text { Safety of } \\
\text { Flight }\end{array}$} & Controllability & $\begin{array}{l}\text { Frequency of control loss } \\
\text { and collisions. }\end{array}$ & \multirow{2}{*}{$\begin{array}{l}\text { Outcome is expanded VFR and IFR operational } \\
\text { parameters in all weather and visibility } \\
\text { conditions. }\end{array}$} \\
\hline & Pilot Workload & $\begin{array}{l}\text { Percent of pilot tasks } \\
\text { supplemented or overtaken } \\
\text { by automation. }\end{array}$ & \\
\hline
\end{tabular}

American Institute of Aeronautics and Astronautics 


\begin{tabular}{|c|c|c|c|}
\hline \multirow[t]{2}{*}{$\begin{array}{l}\text { TOP- } \\
\text { LEVEL } \\
\text { METRIC }\end{array}$} & $\begin{array}{l}\text { MID-LEVEL } \\
\text { METRIC }\end{array}$ & $\begin{array}{l}\text { METRIC } \\
\text { DEFINITION/UNITS }\end{array}$ & ASSUMPTIONS/COMMENTS \\
\hline & $\begin{array}{l}\text { System } \\
\text { Reliability }\end{array}$ & $\begin{array}{l}\text { VLA system failures/ } \\
100,000 \text { flight hours. }\end{array}$ & $\begin{array}{l}\text { Reference MIL-STD-756, MIL-HDBK-217, and } \\
\text { or other applicable standards. }\end{array}$ \\
\hline \multirow[b]{2}{*}{$\begin{array}{l}\text { State of the } \\
\text { Art }\end{array}$} & $\begin{array}{l}\text { An Array of } \\
\text { Validated } \\
\text { ModSim Tools } \\
\text { for VLA } \\
\text { Developers } \\
\end{array}$ & $\begin{array}{l}\text { Number and fidelity of } \\
\text { validated tools, algorithms, } \\
\text { models, and simulations } \\
\text { for VLA analysis, design, } \\
\text { testing, and operations. }\end{array}$ & \\
\hline & $\begin{array}{l}\text { Certification } \\
\text { Standards }\end{array}$ & $\begin{array}{l}\text { Analytical assessment of } \\
\text { certifiability for all VLA } \\
\text { systems and sub-systems. } \\
\text { Certification path for VLA } \\
\text { configurations and } \\
\text { propulsion systems } \\
\text { (conventional and } \\
\text { electric). }\end{array}$ & \\
\hline $\begin{array}{l}\text { Synergy } \\
\text { with DoD }\end{array}$ & $\begin{array}{l}\text { Technology } \\
\text { Transfer } \\
\text { Opportunities }\end{array}$ & $\begin{array}{l}\text { Extent of technology } \\
\text { adoption between DOD } \\
\text { and NASA. }\end{array}$ & $\begin{array}{l}\text { Data exchange on electrified aircraft propulsion } \\
\text { and alternative fuel technologies between } \\
\text { NASA and DoD. Extent of cooperation between } \\
\text { NASA and DoD through Communities of } \\
\text { Interest (COI) on electrified aircraft propulsion } \\
\text { and alternative fuel. }\end{array}$ \\
\hline
\end{tabular}

\section{H. Rationale for the Metrics of Thrust 3B, Ultra-Efficient Commercial Vehicles--Vertical Lift Aircraft}

Increased operational access into congested, noise sensitive urban areas was chosen because it presented a nonprescriptive metric for expanded VLA access. However, the rate at which the aviation industry can expand utilization of VLAs will also be strongly governed by the pace of authorities adopting new regulations enabling new VLA missions and operating locations.

Overall emission reductions are measureable and achievable by either utilizing low-carbon "life-cycle" fuels and/or electricity derived from low-carbon "life-cycle" generation. One significant influence on these reduced emissions metrics will be the availability of the new fuels in quantities sufficient to support operational requirements. Simply reducing the aircraft's "Energy Intensity" will also result in a measurable decrease in emissions as a result of decreasing the amount of fuel or electricity that is required for flight.

The Energy Intensity metric can also be quantified through measurable reduction of the vehicle's aerodynamic drag which would result in reducing the energy required to fly at a given speed and weight. A parallel aspect of this metric is to measure the increased propulsion system efficiencies that also can reduce the amount of fuel or electricity needed for a given speed and weight. A related measurement calls for improvement in the power-to-weight ratio of the engine and a reduction in power loss due to transmission inefficiencies (friction and heat).

The metrics used for classic cost measurements, which are composed of several lower-level measurements, are appropriate for VLAs as well but will vary according to the aircraft design and the way the aircraft is operated.

The development of new markets and applications was predicated on several assumptions. Incorporation of new VLA technologies by industry operators will enable the unspecified new performance capabilities required for expanded operations. The increased number of aircraft employing Thrust 3B technologies provided a direct measurement of technology adoption. Here too the rate of expansion will be influenced by the pace of new regulation development. We also recognized that there may be a degree of equipment displacement VLAs could have over conventional fixed wing aircraft and even ground transportation on trips of 500 miles or less. Expansion of the Range of Operations is a metric that has a direct increase on vehicle range which in turn would provide greater VLA operational flexibility and mobility. One obstacale to expanding VLA markets and applications is the extent to which the traveling public has confidence in these new aircraft.

Noise was identified as a common metric for all certified aircraft and can best be determined in accordance with established FAA and ICAO standards.

Safety for Thrust 3B was characterized as Safety of Flight as measured by controllabilty in addition to pilot workload. This includes overall safety of flight as it was perceived to be by the VLA industry and the communities

American Institute of Aeronautics and Astronautics 
they would serve. System Reliability for VLA vehicles (especially those incorporating the new Thrust 3B technologies) will be challenging to characterize on a fleet operations basis due to the lack of a comprehensive knowledge base for the new technologies Thrust 3B will be introducing. Owing to the large number of new technologies and systems planned for VLA vehicles, the existing reliability standards provide a reasonable starting point, though other measuring standards may also be applicable.

State of the Art is a broad term for capturing the development of a wide variety of validated ModSim tools that VLA manufacturers need to provide them with a solid analytical "toolbox" of algorithms, models, and simulations for subsequent design and testing of new VLA vehicles. The essential measurement is the number of ModSim tools and the extent of their utility and use for enabling aircraft manufacturers to develop, build, and certify Thrust 3B aircraft. A path for certification compliance for VLA airframe configurations and propulsion systems is essential if VLA vehicles employing these new systems are to enter service. This pathway can be supported by establishing an analytical method of determining the extent to which new VLA systems and subsystems are potentially certifiable, and what must be done to bring them through the FAA certification process.

Lastly, the synergy between NASA and the national security and defense (DoD, DHS, etc.) sector has been significant but the divers range of technology objectives, i.e., safety versus mission requirements, made developing defined metrics difficult. The best metric seemed to be found in the extent of data exchanges between NASA and the DoD on Thrust 3B research topic areas.

\section{Conclusion and Recommendation}

This task to develop Strategic Thrust Outcome benefit metrics was a "Bottom Up" assessment that directly describes each of the Strategic Thrust Outcome Benefits. The methodology was developed and applied across all six ARMD Strategic Thrusts. This paper used the specific work done for Thrust 3B to illustrate the process and provide the resulting metrics for Thrust 3B. It provides a comprehensive and relevant set of measurement data for ARMD to utilize to effectively assess the Thrust 3B program objectives and progress. Because the set of metrics developed for Thrust $3 \mathrm{~B}$ was mapped directly to the Thrust $3 \mathrm{~B}$ research, it is available as a valuable resource for ARMD to manage the Thrust 3B research investment portfolio, update the SPMR dashboard, and update the ARMD database.

The Strategic Thrust 3B metrics will serve to assess the NASA VLA research progress. The metrics provide one way to measure of the connection between the research and desired community Outcomes. It is recommended that the next steps in ARMD metrics development apply the Mid-Level metrics from this work in a demonstration assessment to determine if the metric methodology across the Strategic Thrusts is robust and consistent. Successful application of the metrics would give ARMD additional insight to manage program portfolios and provide an effective measure of progress towards the goals of the Strategic Implementation Plan.

\section{References}

\footnotetext{
${ }^{1}$ ARMD, (2017). NASA Aeronautics - Strategic Implementation Plan. Aeronautics Research Mission Directorate, Retrieved from: https://www.nasa.gov/sites/default/files/atoms/files/sip-2017-03-23-17-high.pdf

${ }^{2}$ Susan Gorton and Rich Wahls, (2016). ARMD Strategic Thrust 3. Retrieved from: NASA Vertical Lift Strategic Direction: https://www.nasa.gov/sites/default/files/atoms/files/armd-sip-thrust-3b-vertical-lift-508.pdf

${ }^{3}$ Neitzke, Kurt W. and Smith, Jeremy C. "Metrics for the NASA Airspace." NASA Langley Research Center, Retrieved from: https://ntrs.nasa.gov/search.jsp?R=20090042518

${ }^{4}$ NASA, n.d., SMART and Performance Criteria. Retrieved from: https://nasa.asu.edu/files/documents/SMARTand\%20Performance\%20Guidelines.pdf
}

American Institute of Aeronautics and Astronautics 